\title{
Author Correction: Unfolding political attitudes through the face: facial expressions when reading emotion language of left- and right- wing political leaders
}

\author{
Edita Fino $\mathbb{D}$, Michela Menegatti, Alessio Avenanti \& Monica Rubini
}

Correction to: Scientific Reports https://doi.org/10.1038/s41598-019-51858-7, published online 30 October 2019

The original version of this Article contained an error in Affiliation 3, which was incorrectly given as 'Department of Psychology, Alma Mater Studiorum University of Bologna, Bologna, Italy’. The correct affiliation is listed below.

Department of Psychology, Alma Mater Studiorum University of Bologna, 40126, Bologna, Italy

Additionally, Alessio Avenanti was incorrectly affiliated with 'IRCCS Fondazione Santa Lucia, Roma, Italy'. The correct affiliations are listed below.

Department of Psychology, Alma Mater Studiorum University of Bologna, 40126, Bologna, Italy

Centro de Investigación en Neuropsicología y Neurociencias Cognitivas, Universidad Católica del Maule, 3460000, Talca, Chile

These errors have now been corrected in the PDF and HTML versions of the Article.

(c) (i) Open Access This article is licensed under a Creative Commons Attribution 4.0 International Cicense, which permits use, sharing, adaptation, distribution and reproduction in any medium or format, as long as you give appropriate credit to the original author(s) and the source, provide a link to the Creative Commons license, and indicate if changes were made. The images or other third party material in this article are included in the article's Creative Commons license, unless indicated otherwise in a credit line to the material. If material is not included in the article's Creative Commons license and your intended use is not permitted by statutory regulation or exceeds the permitted use, you will need to obtain permission directly from the copyright holder. To view a copy of this license, visit http://creativecommons.org/licenses/by/4.0/.

(C) The Author(s) 2020 